\title{
Application of multi-criteria methods to compare different solutions of supplying buildings in electricity from photovoltaic systems
}

\author{
Barbara Mendecka ${ }^{1}$ and Alicja Stoltmann²,a \\ ${ }^{1}$ Industrial Engineering Department, Florence University, Italy \\ ${ }^{2}$ Faculty of Electrical and Control Engineering, Gdańsk University of Technology, Poland
}

\begin{abstract}
Nowadays, the technologies of electricity generation in distributed systems are usually associated with Renewable Energy Sources (RES). The choice of the construction site depends mainly on the availability of the power system. However, energy planning, especially in case of RES, is a complex process involving multiple and often conflicting objectives. The complexity of the selection of the electricity system is typically addressed with the use of multi-criteria tools, involving all of the considered criteria and also different methods of their aggregation. The result is a final ranking of the available alternatives. This paper describes the application of a multi-criteria decision tool for the comparative analysis of the use of alternative options of the PV technology for electricity production. Four decision variants are considered, including the different construction of solar farms (static and movable structure) and different types of configuration of individual installation (off and on-grid). The construction of each new sources of electricity generation, including PV, is the multi-threaded and multi-dimensional decision problem. The criteria used in the analysis combine economic, environmental and social issues. The first of the considered criterion is the Net Present Value (NPV) which determines the economic viability of the project. The second criterion, thermo-ecological cost (TEC), connecting energy and environmental issues. Finally, the Land Use (LU) is considered as a social criterion. As aggregation function, the Weighted Sum Method (WSM) is used. The sensitivity analysis of the criteria weights was performed with the use of a novel method involving Monte Carlo simulation and a method of data reconciliation.
\end{abstract}

\section{Introduction}

One of the main consequences to the accession to the European Union (EU) by member countries is the transformation process in all sectors of economy, as well as in the energy one.

Concerning the latter, one of the essential points is the reduction of emissions of greenhouse gasses. This aspect leads to the needs of developing renewable technologies and reducing the amount of existing nonrenewable energy sources. Renewable Energy Sources (RES) are those sources of energy that are naturally regenerated over a short time scale and they are, for this reason, considered inexhaustible. RES include energy from wind, water, sun, geothermal heat, wave, tidal and biofuels.

Deployment of energy from RES in the EU member states is regulated by documents and normative acts of the EU, mainly [1]. Specifically, as far as Poland concerns, such regulations are contained in the legislation through the Environmental protection Low Act [2] and the Energy Law Act [3]. In the framework of environmental obligations, the EU has set quantitative targets for 2020 time horizon ( $3 \times 20 \%$ energy package). Such targets contain: a reduction in greenhouse gas emissions by $20 \%$ compared to 1990; a reduction of energy consumption by $20 \%$ compared to projections for 2020 ; an increasing of the share of renewable energy to $20 \%$ of the total energy consumption with, in particular, an increasing of the use of renewable energy sources in transport to $10 \%$.

Recently, a report by the Intergovernmental Panel for Climate Change pointed out the risk of an increasing of global temperature up to $3-5{ }^{\circ} \mathrm{C}$, if the $\mathrm{CO}_{2}$ concentration will keep increase, which would lead to dramatic consequences for the earth [4]. Energy production by means of RES may represents a possible solution, which may lead to a reduction of the environmental impact of the energy production sector Polish Energy Policy establishes an increase of the share of energy from RES up to $7 \%$ of the total energy production within the 2030 [5].

The Polish power system of the southern part of the country, which is particularly developed, is a centralized system, characterized by low substantial losses in electric energy transfer (such losses are proportional to the transfer distance). In contrast, due to the low number of large power generation sources in the northern Poland, the power system of such area is non-centralized. Because of this, the northern Poland (especially the north-east region of Poland) is the most suitable place for investment in distributed generation [6]. Distributed generation, due to the nature of production

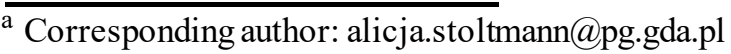


may be a good solution to ensure energy supply to objects who have no access to the grid [7]. Currently, in EU, one of the most developed system from RES is the photovoltaic one (PV), as well as the thermal and concentrated solar power technologies. It is estimated that, in UE $178 \mathrm{GW}_{\mathrm{p}}$ $\left(\mathrm{W}_{\mathrm{p}}\right.$-power measured in Standard Test Conditions) in the EU energy comes from PV installations. Among the members of UE Germany is the country which is characterized by the highest $\mathrm{PV}$ energy production rate in (474.1 $\mathrm{W}_{\mathrm{p}}$ per capita). It follows Italy with $303.5 \mathrm{~W}_{\mathrm{p}}$ per capita. In Poland, the production rate from PV technology is $0.6 \mathrm{~W}_{\mathrm{p}}$ per capita (with a total production in $\mathrm{PV}$ installations of $39.2 \mathrm{MW}_{\mathrm{p}}$ ) which data demonstrates that the photovoltaic market in this country is developing [8]. The Institute of Renewable Energy predicts that in the next two years the price of PV installations will drop significantly, causing an increasing interest in this way of energy production. Additionally, the latest legal regulations, introducing the concept of prosumer (defined as a person who consumes and produces a media) [8] assisted by subsidy programs [9], will contribute to the development of small PV systems that can be used by individual users.

The electricity demand can be cover by the production of energy both in a residential installation as well as in photovoltaic power plants. Such solutions have a common drawback, which is the cost of installation per $1 \mathrm{~kW}$ of installed capacity, being this the reason why PV installations still require to be subsided. On the other hand, advantages of PV installations concern the reduction of transmission losses and the fact that the technology is environmentally friendly.

The Polish legislation, classify energy production from PV installations as a distributed energy sources, that results in low-power sources connected to the distribution network. Distributed energy sources include sources with installed capacity not exceeding $50 \mathrm{MW}$. The PV technology is characterized by a direct processing of the primary energy into electrical energy. PV installations can be of 'on-grid' as well as 'off grid' type, depending whether the installation is connected to the grid [10].

In case of 'on-grid' system, voltage parameters do not depend on the source state. This because a PV installation is affected by voltage drops due to the impedance of the connection line between the source and the grid. When working off-grid, PV installation influences the parameters of the network [11].

Moreover, PV installations do not work continuously. Therefore, it is necessary to store the exceeding energy in order to provide it when necessary or to deliver it to, higher power hybrid systems that are those systems consisting of renewable and non-renewable energy sources. Few example of such systems are the wind and PV technology [12], and the Diesel engine [13]. In the recent literature, much attention is given to the design and the modeling of PV installations [12], [14], [15]. Selection of PV installations and its location is a multi-criteria decision problem. A great amount of works focusing on PV construction projects and in decision making processes are available in literature. Among these, the Multi-Criteria Decision
Making methods (MCDM) is one of the most interesting and used. In [16], [17] the Preference Ranking Organization METHod for Enrichment Evaluations (PROMETHEE) model is used to choose the most suitable energy policy among many possibilities which include the employment of small and large size PV installations. In order to choose the most sustainable electricity production technology, the multi-criteria Technique for Order Preference by Similarity to Ideal Solutions (TOPSIS) was presented in [18]. Another popular multicriteria method is the Analytic Hierarchy Process (AHP), which was applied in [19] to help a Spanish company in the decision making process concerning the investment for a particular solar power plant project. In [20] the Weighted Sum Method (WSM) for the quantification and evaluation of the potentials of available PV was presented. The use of fuzzy (linguistic) quantifiers for specified parameters in multi-criteria evaluation procedure, which is based on GIS-based analysis, was presented in [21] to assess the land suitability for large PV farms. The combination of GIS and MCDM methods for side selection studies are widely used, for example in [22], to determine suitable site selection for solar farms by using GIS and AHP in the study area, and in [23] using GIS and Analytic Hierarchy Process (AHP) method to weight the criteria in order to evaluate potential sites to locate a solar plant.

It has been observed that, in polish solar exposure conditions, both on-grid and off-grid PV individual installations are not economically profitable. In contrast, it is estimated that PV farms may be suitable to cover the electricity demand of whole towns.

The aim of the present study is to analyze and compare the different options of employing PV technology to electricity supply in the rural areas of the northern Poland. The assessment is made using a multi-criteria decision tool in order to compare the specified variants of the electricity generation including different types of PV farm construction (with static and movable structure) and different configuration of individual installations (off-grid and on-grid). The criteria used in the analysis combine economic, environmental and social issues. The first of the considered criterion is the Net Present Value (NPV) which determines the economic viability of the project. The second criterion, thermo-ecological cost (TEC), connecting energy and environmental issues. Finally, the Land Use (LU) is considered as a social criterion. As aggregation function, the Weighted Sum Method (WSM) is used. The sensitivity analysis of the criteria weights is performed with the use of a novel method involving Monte Carlo simulation and a method of data reconciliation.

\section{Material and methods}

Multi-criteria decision analysis (MCDA), which engages economic, environmental and social issues through participatory and analytical tools, is widely adopted for energy technologies selection. Moreover, multi-objective methods provide decision makers with an opportunity to negotiate and explore the different 
decision options. Complex interactions among multiple objectives (goals) have insisted to integrate multi-criteria assessment techniques in the framing of appropriate energy management directions.

MCDA is also a form of integrated sustainability evaluation and can be defined by a General Index of Sustainability [24]. In the present study, to perform such evaluation, the generic multi-criteria approach base on the Weighted Sum Method (WSM) is proposed.

Three different criteria in terms of economic, environmental and social impacts are also defined.

For the economic assessment, the Net Present Value (NPV, also known as Net Present Worth, NPW [25]) which is defined as the sum of the present values of incoming and outgoing cash flows over a period of time, is proposed. In the profitability analysis of investments such criterion represents a standard method to appraise long-term energy projects. Used for capital budgeting, it measures the excess or shortfall of cash flows, in present value terms, once financing charges are met. Also, it is often used to assess the early stage of decision making process [25], [26]. The NPV indicator is given by the following formula:

$$
N P V(i, N)=\sum_{t=0}^{N} \frac{R_{t}}{(1+t)^{t}}
$$

where:

$t$ is the time of cash flow, $i$ is the discount rate and $R_{t}$ represents the net cash flow.

A positive value for the NPV indicates that the projected earnings generated by a project or investment overcome the anticipated costs. Thus, if the NPV is positive, it means that the investment is profitable and the project may be accepted. On the contrary, a negative value for the NPV indicates a net loss for the investment and the project should be rejected.

To consider environmental implication of electricity produced in a PV systems, the impact assessment is carried out using thermo-ecological cost analysis in whole life-cycle (TEC-LC). According to J. Szargut [27], [28] the TEC-LC indicator is defined as the cumulative consumption of non-renewable exergy connected with the manufacturing of a particular product. The TECLC includes, in addition, the consumption resulting from the necessity of compensation of environmental losses caused by rejection of harmful substances in the natural environment. The detailed description of the TEC-LC method, including the set of equations, can be found in [29], [30] and for this reason is not reported here. In previous works, TEC referring to RES was implemented, for example, to optimize solar collector used for production of hot water [31], as well as for evaluation of biofuel conversion processes [32] or electricity produced in micro- wind turbines [33]. The total thermo-ecological cost can be presented as follows:

$$
T E C L C_{\text {total }}=T E C \cdot(D R+I F+E)
$$

Where:

$D R$ - direct resources

$I F$ - instant flows

$E$ - emissions
The social criterion, the Land Use (LU) is defined as an external urban area required for the PV plant construction.

The selected functional unit for the comparison was $1 \mathrm{kWh}$ of produced electricity, assuming a service life time equal to 25 years.

As mentioned before, the multi-criteria approach applied in this work employs the Weighted Sum Method as an aggregated objective function.

Since, the considered criteria are characterized by different units, the normalization procedure is required. Normalized value of the $\mathrm{j}$-th criterion is calculated using the following equation:

$$
\begin{aligned}
& \bar{C}_{j}=\frac{\Delta C_{j}}{C_{j, \max }-C_{j, \min }} \\
& \text { where }\left\{\begin{array}{c}
\Delta C_{j}=C_{j}-C_{j, \min } \text { for benefit criteria } \\
\Delta C_{j}=C_{j, \max }-C_{j} \text { for cost criteria }
\end{array}\right.
\end{aligned}
$$

After criteria normalization, the aggregated objective function is defined as follows:

$$
\bar{C}=\sum_{i=1}^{n} W^{T} \bar{C}_{j}
$$

where:

$$
\mathbf{W}=\left\{w \in R \quad: w \geq 0 \quad \sum_{j=1}^{M} w_{j}=1\right\}
$$

$\boldsymbol{w}$ is a vector of weights of the decision criteria.

Finally, a ranking of the analyzed solutions is determined. An optimal solution is a variant with the maximal value of the aggregated objective function (eq.4).

Since their subjective features, the criteria weights are the uncertain parameters in the decision model. Thus, the uncertainty analysis of the final results has to be performed. For this purpose, the novel method of minimizing the uncertainty of criterion weight functions using Monte Carlo simulation and method of data reconciliation is applied. Fully description of this method is presented in [34].

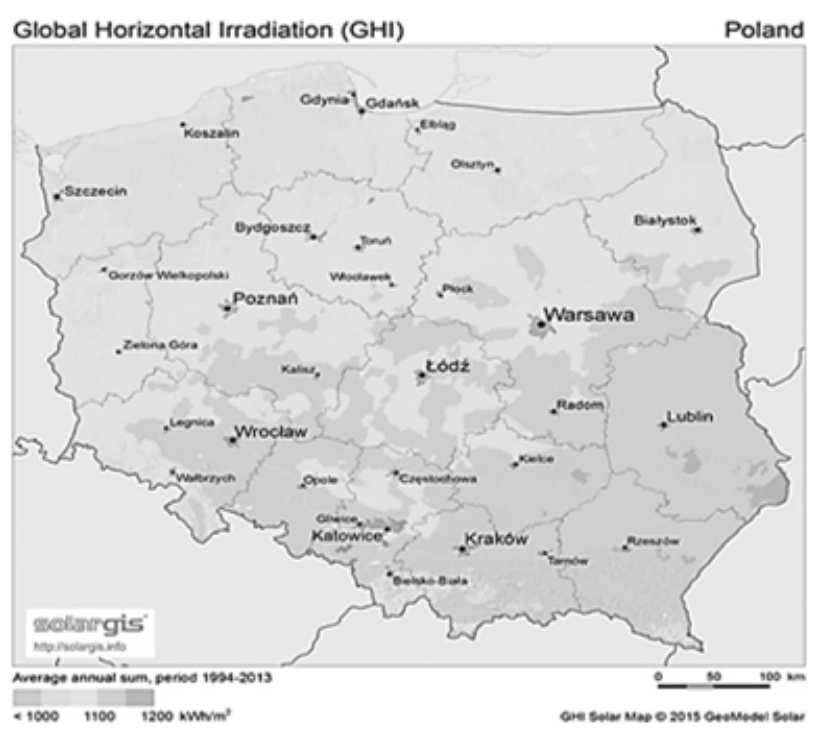

Figure 1. Solar radiation density in the Borkowo on the background of Poland [36] 
Table 1. Monthly sunshine hours

\begin{tabular}{|c|c|c|c|c|c|c|c|c|c|c|c|c|c|}
\hline Month & I & II & III & IV & V & VI & VII & VIII & IX & X & XI & XII & $\boldsymbol{\Sigma}$ \\
\hline Sunshine hours [h] & 239,6 & 264,8 & 360,4 & 417,2 & 492,5 & 506,34 & 503,52 & 445,88 & 363,9 & 305,7 & 238,4 & 220,9 & 4359 \\
\hline
\end{tabular}

\section{Results}

The comparative analysis of the alternative solutions of the electricity generation from PV systems is performed for the case study Borkowo. Borkowo is a town located close to the city of Gdansk, in the Pomorskie Voivodship. This particular region is characterized by an average insolation of $1000 \mathrm{kWh} / \mathrm{m}^{2}$ per month. About the $80 \%$ of the total annual insolation occurs during six months of the year, from April till

September. Moreover, during the summer months, the sunshine hours are about $16 \mathrm{~h}$ per day while in winter $-8 \mathrm{~h}$ per day [35].

Table 2. Case study assumptions

\begin{tabular}{|c|c|c|}
\hline & Area, $\mathbf{m}^{2}$ & $\begin{array}{c}\text { Electricity } \\
\text { de mand, } \\
\text { MWh/a }\end{array}$ \\
\hline Single-family buildings & 5408 & 1372 \\
\hline Multi-family buildings & 978 & 360 \\
\hline Individual public utility buildings & 946 & 1076 \\
\hline School and kindergarten & 2630 & 329 \\
\hline
\end{tabular}

As it is shown in Table 1, the total hours of sunshine (length of day) are $4359 \mathrm{~h}$ per year, with about $500 \mathrm{~h}$ per month during five spring-summer months. Therefore, this area is worth of attention in case of building PV installation. Furthermore, in Pomorskie Voivodship, in the Ustronie Morskie community, there is currently a 1MWp PV farm located on former waste dump. The plant supplies electricity to community buildings and allows to save $80-90 \%$ of the electricity costs of the communityThe electricity demand in the selected case study concern the consumption in the single and multi-family buildings, two individual public utility buildings, a trade and a service area, a school and a kindergarten. In the present analysis, it is assumed that the energy demand for individual public utility buildings is entirely covered from the power grid. Also, the energy produced from PV installations is assumed to not cover the domestic hot water heating. The estimated electricity demand for the present case is presented in the Table 2 .

In order to cover the electricity demand, four different solutions for the electricity supplying by a PV installations are proposed. In the first variant (Variant I) the electricity is delivered from a PV farm mounted on a fixed structure. In the second scenario (Variant II), the construction of the solar farm is located on a mobile servo system, which allows to obtain a higher amount of electricity production than the fixed structure. In the next alternative solution (Variant III), it is assumed that electricity is delivered from the individual off-grid PV installations. In this case, the recipient uses energy derived from a PV installation at the same time of the production or, in case, it uses energy that has been previously accumulated in batteries during a lack of demand. In absence of available energy, this needs to be acquired from the power grid. The last option(Variant IV) considers that the electricity is produced by individuals on-grid PV installations. This allows to sell electricity to the power grid when the PV installation produces energy, whenever the demand is fulfilled. The characteristic of the analyzed solutions is presented in the Table 3 . The results of energy analysis are shown in the Table 4.

Table 4. Energy generation in the analyzed PV options

\begin{tabular}{|c|c|c|c|}
\hline & Type & $\begin{array}{c}\text { PV output, } \\
\text { MWh/a }\end{array}$ & $\begin{array}{c}\text { De ficit, } \\
\text { MWh/a }\end{array}$ \\
\hline Variant I & PV farm static & 15708 & 0 \\
\hline Variant II & PV farm movable & 21069 & 0 \\
\hline Variant III & Individual off-grid & 5906 & 123 \\
\hline Variant IV & Individual on-grid & 5906 & 213 \\
\hline
\end{tabular}

Table 3. Characteristics of the analyzed PV alternatives

\begin{tabular}{|c|c|c|c|c|c|c|c|}
\hline & Description & $\begin{array}{c}\text { PV } \\
\text { are a, } \\
\mathbf{m}^{2} \\
\end{array}$ & Type of PV & $\begin{array}{l}\text { Number of } \\
\text { inverters }\end{array}$ & $\begin{array}{l}\text { Type of } \\
\text { inverter }\end{array}$ & $\begin{array}{l}\text { Number of } \\
\text { batteries }\end{array}$ & $\begin{array}{l}\text { Type of } \\
\text { battery }\end{array}$ \\
\hline Variant I & PV farm static & 11048 & $\begin{array}{c}\text { Mono-Si } \\
\text { ZXP6-60- } \\
240 \\
\end{array}$ & 369 & $\begin{array}{c}\text { Sunny Boy } \\
3300\end{array}$ & - & - \\
\hline Variant II & PV farm movable & 11048 & $\begin{array}{c}\text { Mono-Si } \\
\text { ZXP6-60- } \\
240 \\
\end{array}$ & 369 & $\begin{array}{c}\text { Sunny Boy } \\
3300\end{array}$ & - & - \\
\hline Variant III & Individual off-grid & 11241 & $\begin{array}{c}\text { Mono-Si } \\
\text { ZXP6-60- } \\
240\end{array}$ & 1153 & $\begin{array}{c}\text { Sunny Boy } \\
1200\end{array}$ & 1776 & $\begin{array}{c}\text { Victron } \\
\text { Energy GEL } \\
12 \mathrm{~V} / 220 \mathrm{Ah}\end{array}$ \\
\hline Variant IV & Individual on-grid & 11241 & $\begin{array}{c}\text { Mono-Si } \\
\text { ZXP6-60- } \\
240\end{array}$ & 1068 & $\begin{array}{c}\text { Sunny Boy } \\
1200\end{array}$ & - & - \\
\hline
\end{tabular}




\subsection{Economic analysis}

The NPV is calculated on the basis of the current price data. In order to predict the electricity price during the next 25 years, an average evolution rate of the electricity price is calculated based on the past 25 years (2\%). The base value of electricity price for the first year of the analysis is assumed to be equal to $445 \mathrm{zz} / \mathrm{MWh}$ for the Variants I and II [37] and $750 \mathrm{zz} / \mathrm{MWh}$ for the Variant IV [38]. The total investment costs are shown in the Table 5. The contribution of particular

Table 5. Total investment cost

\begin{tabular}{|c|c|c|}
\hline & Type & Total inves tment cost, zt \\
\hline Variant I & PV farm static & 7397290 \\
\hline Variant II & PV farm movable & 8642096 \\
\hline Variant III & Individual off-grid & 11697352 \\
\hline Variant IV & Individual on-grid & 9670265 \\
\hline
\end{tabular}

Source: primary data

system elements in the total investment cost is presented in Fig. 2.

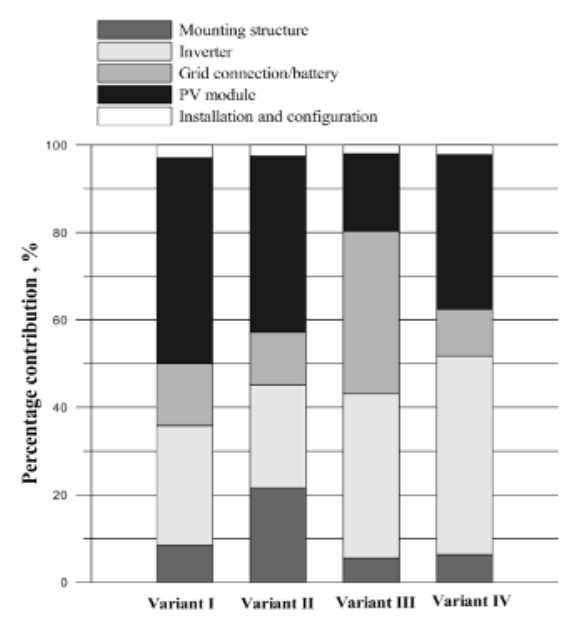

Figure 2. Contribution of the system components in the total investments cost.

In case of scenario I and II, the highest contribution to the investment cost is related to PV modules. However, for the scenario III, the grid connection and battery costs are the most significant, while for scenario IV, the inverter cost is the highest. The costs of installation and configuration give the lowest contribution for all of the analyzed cases.

The NPV in terms of electricity produced within 25 years is depictedinFig. 3. The NPV is the benefit criterion. Thus, the maximal value refers to the optimal solution.

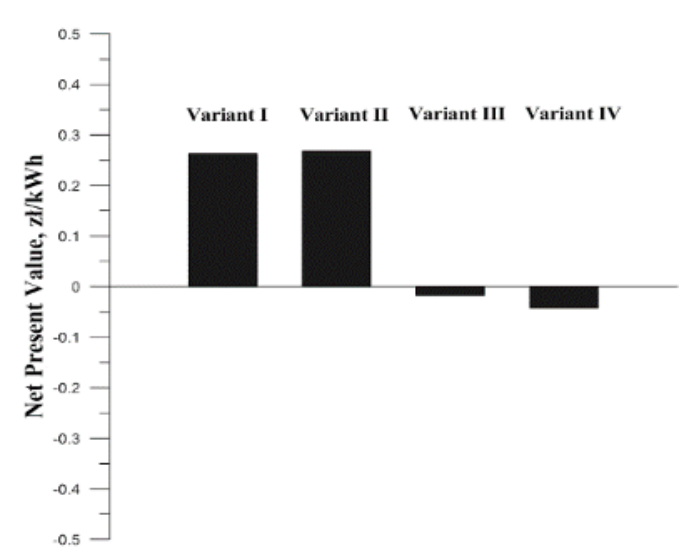

Figure 3. Net Present Value in terms of electricity produced within 25 years

Comparing the analyzed alternative solutions, the choice of variant II with movable PV farm seems to be the most economically justified. In this case, the highest positive effect is due to the highest rate of electricity produced and sold to the grid. The worst scenario from the economic point of view is the employing of the individuals 'on-grid' $\mathrm{PV}$.

\subsection{Environmental analysis}

The thermo-ecological cost include the construction and operational phases and is calculated using eq.2. The data on processes and materials are collected on the basis of technical specification of the devices as well as other system elements. The data on the cumulative exergy demand due to material consumption are retrieved from the Ecoinvent database and [29], while the exergetic costs of compensation for harmful substances are assumed on the basis of [30] (Table.6). The total thermo-ecological cost of the analyzed systems is presented in the Table. 7

Table 6. Thermo-ecological cost of harmful substances

\begin{tabular}{|c|c|c|}
\hline Substance & External cost, EUR/kg & $\begin{array}{c}\text { Cost of } \\
\text { compensation, } \\
\mathbf{k J} / \mathbf{k g}\end{array}$ \\
\hline $\mathrm{SO}_{2}$ & 8.24 & 37.8 \\
\hline $\mathrm{NOx}$ & 4.07 & 18.7 \\
\hline $\mathrm{PM}$ & 3.99 & 18.3 \\
\hline
\end{tabular}

Table 7. The total thermo-ecological cost of the analyzed systems

\begin{tabular}{|c|c|c|c|}
\hline & $\begin{array}{c}\text { TEC, } \\
\text { construction } \\
\text { phase, } \mathbf{M J}_{\mathbf{e x}}\end{array}$ & $\begin{array}{c}\text { TEC, } \\
\text { ope rational } \\
\text { phase, } \mathbf{M J}_{\mathbf{e x}}\end{array}$ & $\begin{array}{c}\text { Total TEC, } \\
\mathbf{M J}_{\mathbf{e x}}\end{array}$ \\
\hline Variant I & 78386152 & 0 & 78386152 \\
\hline Variant II & 87776761 & 0 & 87776761 \\
\hline Variant III & 52517935 & 1599 & 52519534 \\
\hline Variant IV & 41367957 & 2766 & 41370724 \\
\hline
\end{tabular}

The results are expressed in terms of unit of electricity produced by the PV panels within the whole life cycle (25 years) and are shown in Fig. 4. The TEC-LC is the 
cost criterion. Thus, the minimal value refers to the optimal solution. In Fig. 5, the influence of the different system components on the total value of TEC is presented.

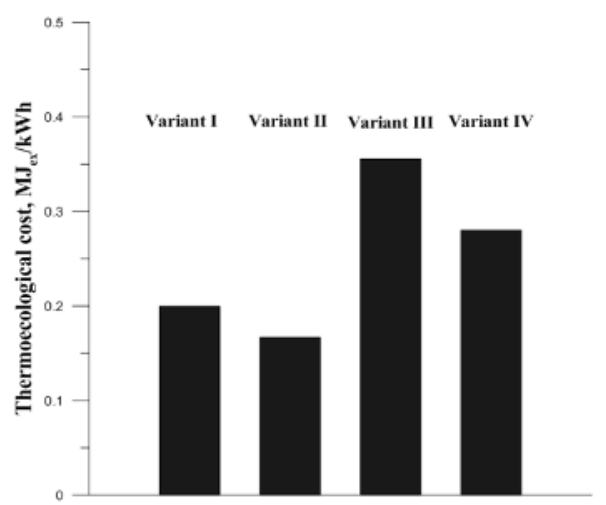

Figure 4. Thermo-ecological cost in terms of electricity produced within 25 years

Comparing the TEC-LC results, the same variant (variant II - PV movable farm) as in economic analysis, is indicated as the most preferable.

Analyzing the component contributions, it can be also observed that the most influencing component for the variants I and II is the mounting structure. This is due to high concrete and steel consumption, which are characterized by the high exergy consumption. On the contrary, for individual systems, the PV panels production contribute the most in total energy consumption.

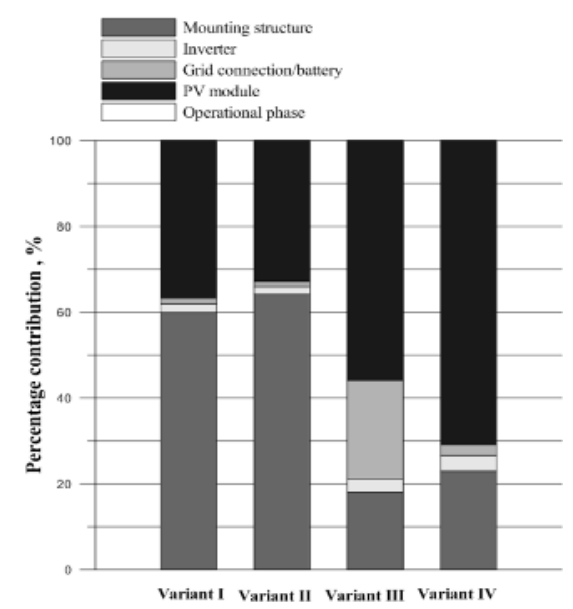

Figure 5. Contribution of the system components in the total thermo-ecological cost

\subsection{Social analysis}

The social criterion is determined by any additional external urban area required for the PV plant construction. Such factor is often the major constraint in the energy technology choice.

For the PV farm plants (variant I and II), the Land Use is estimated assuming the area of a single PV panel and the distance between the panels. Thus, for static installation (variant I), the total Land Use is equal to 2.97 ha, while for dynamic structure (variant II), which in general requires more space, is equal to 3.78 ha.
In the options employing PV panels for individual use which are installed on the rooftop of the buildings, any external urban area is not required. Thus, for those cases, the LU equal to 0 . Similarly to TEC-LC, the Land Use is a cost criterion.

In Fig. 6, the results, in terms of electricity produced, are presented. Comparing the ranking for this criterion with the previous ones, an opposite result is obtained.

\subsection{Multi-criteria analysis}

Since the economic, environmental and social analysis give a different conclusion, the multi-criteria approach is in this case justified. Firstly, the ranking of the alternative solutions is evaluated assuming deterministic weights that are equal to each other. The normalized values of the criteria as well as the value of the aggregated objective function (eq.3 and 4) are calculated using the data reported in previous sections. The results are shown in Fig. 7

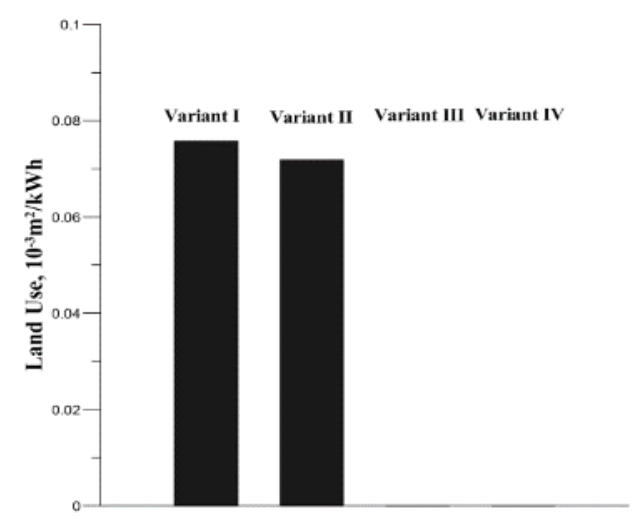

Figure 6. Land Use in terms of electricity produced within 25 years

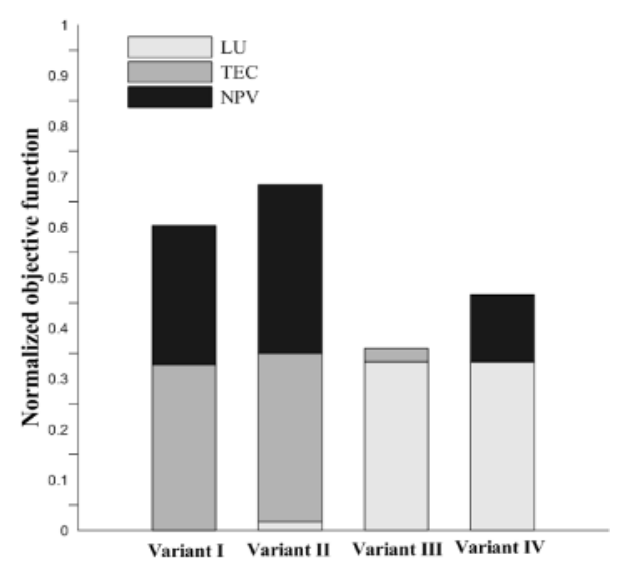

Figure 7. Final ranking of the analyzed scenarios with the determined weights

Considering the deterministic assumption regarding the criteria weights, the variant II is characterized by the maximal value of the aggregated objective function. Nevertheless, the criteria weights are subjective parameter in the model. Variability of this parameters 
has an influence on the final results. Thus, in order to evaluate the uncertainty of the resulting value of the aggregated objective function, a Monte Carlo simulation with a data reconciliation method is conducted. The random values of criteria weights are selected in 10000 runs. After that, the forecast distribution, for the final result, is obtained. The Monte Carlo simulation is performed assuming the highest weight variability described by a uniform distribution between 0 and 1 for all of the considered parameters. Then, in order to fulfill the constrain condition (eq. 5) the weight vector is recalculated in accordance to rules of the reconciliation calculus.

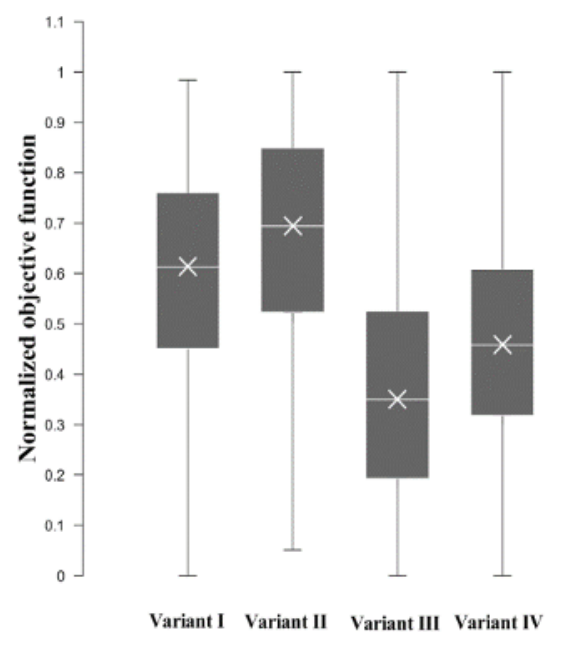

Figure 8. Final ranking of the analyzed scenarios with the uncertain weights

In Fig. 8, the obtained variabilities of the final results are presented. Such variabilities are presented for selected parameters of the probability distribution (min, max, 1st, 2nd and 3rd quartiles). Assuming the marginal weights composition e.g. $(0,0,1)$, the results correspond to those presented in Fig.3, 5 and 6.

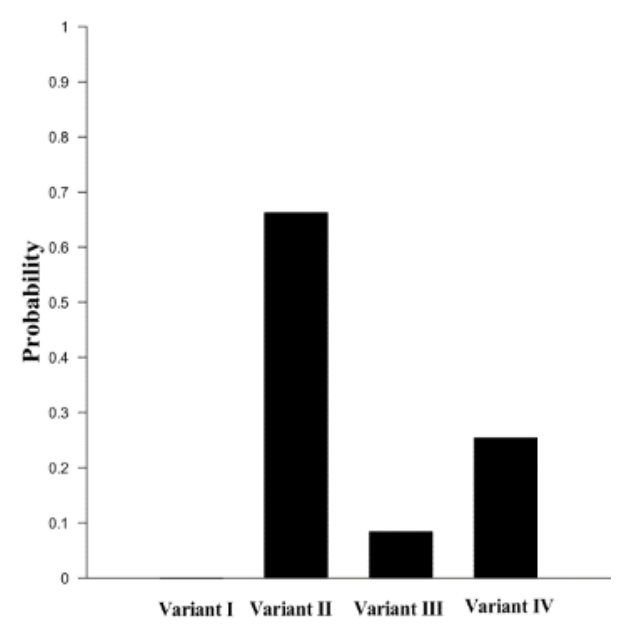

Figure 9. Probability of the ranking score

The results are characterized by high variability. The coefficients of variation for the analyzed scenarios are: $26 \%, 32 \%, 63 \%$ and $44 \%$ for the variant I, II, III, and $\mathrm{IV}$, respectively. In order to determine the most suitable option among all of the analyzed ones, the probability of obtaining the maximal value of the aggregated objective function is evaluated. As it is shown in Fig. 9, variant II is indicated as the preferable solution with the most frequency. Moreover, independently on the criteria weights, the variant I never achieves the maximal value of the objective function. This is because such solution is not preferable, even if the marginal weight vector is assumed.

\section{Conclusions}

The purpose of this study was to analyze the economic, environmental and social impacts due to different alternative solutions of PV use. Four decision variants, including the different construction of solar farms (static and movable structure) and different types of configuration of individual installation(offand on-grid) were compared between themselves. The assessment was carried out using the multi-criteria analysis tool. The first of the considered criterion was the Net Present Value (NPV) which determines the economic viability of the project. The second criterion, thermo-ecological cost (TEC), connecting energy and environmental issues, was evaluated. Finally, the Land Use (LU) was considered as a social criterion. As aggregated objective function, the Weighted Sum Method (WSM) was used. The sensitivity analysis of the criteria weights was also performed using a novel method involving Monte Carlo simulation and a method of data reconciliation.

Results indicate that, for economic and environmental criteria, the solutions considering the PV solar farms are more preferable than individual $\mathrm{PV}$ installations. In case of Land Use, the ranking indicates that the individual PV are more sustainable.

In accordance with multi-criteria ranking, and including high uncertainty of criteria weights, the solution based on the movable PV farm results to be the most effective.

\section{References}

1. 'Directive 2009/28/EC of the European Parliament and of the council of 23 April 2009 on the promotion of the use of energy from renewable sources and amending and subsequently repealing Directives 2001/77/EC and 2003/30/EC', Official Journal of the European Union.

2. 'Environmental protection Low Act (in Polish)', Dz.U. $2001 \mathrm{Nr} 62$ poz. 627.

3. 'Energy Law Act (in Polish)', Dz.U. 1997 Nr 54 poz. 348, vol. 2006, no. 54, 2014.

4. A. Tartaglia, G. Fracastoro, C. Mele, and M. L. Ruggiero, 'The role of renewables in the energy crisis', E3S Web of Conferences, 2, (2014) 
5. National Energy Policy 2030 (in Polish)', Załącznik do uchwały nr 202/2009 Rady Ministrów z dnia 10 listopada 2009 r., 85, 9 (2009)

6. A. Chmielewski, R. Gumiński, J. Mączak, S. Radkowski, and P. Szulim, Ren. and Sust. En. Rev., 60 (2016)

7. J. C. Rojas-Zerpa and J. M. Yusta, Ren. and Sust En. Rev. 52, (2015)

8. 'Instytut Energetyki Odnawialnej'. [Online]. Available: http://ieo.pl/pl/projekty/mikrosieci-iinstalacje-fotowoltaiczne. [Accessed: 02-Apr-2016].

9. 'Renewable Energy Sources Act (in Polish)', Dz. U. z 2015 r. poz. 478, 2365.

10. S. Mandelli, J. Barbieri, R. Mereu, and E. Colombo, Ren. and Sust. En. Rev. 58 (2016)

11. C. P. Vineetha and C. A. Babu, 'Economic Analysis of Off Grid and On Grid Hybrid Power System', IEEE International Conference on Circuit, Power and Computing Technologies, (2014)

12. G. Merei, C. Berger, and D. U. Sauer, 'Optimization of an off-grid hybrid PV-Wind-Diesel system with different battery technologies using genetic algorithm', Solar En. 97 (2013)

13. Y. Li, D. Zhao, and Y. Llu, 'Optimal Design and Sensitive Analysis of Distributed Generation System with Renewable Energy Sources', IEEE China International Conference on Electricity Distribution, (2014)

14. R. Rawat, S. C. Kaushik, and R. Lamba, Ren. and Sust. En. Rev. 57 (2016)

15. M. Obi and R. Bass, Ren. and Sust. En. Rev. 58 (2016)

16. T. Tsoutsos, M. Drandaki, N. Frantzeskaki, E. Iosifidis, and I. Kiosses, En. Pol. 37, 5 (2009)

17. M. Troldborg, S. Heslop, and R. L. Hough, Ren. and Sust. En. Rev. 39 (2014)

18. D. Streimikiene, T. Balezentis, I. Krisciukaitien, and A. Balezentis, Ren. and Sust. En. Rev. 16, 5 (2012)

19. P. Aragonés-Beltrán, F. Chaparro-Gonzalez, J.-P. Pastor-Ferrando, and A. Pla-Rubio, Energy 66 (2014)

20. K. van Alphen, W. G. J. H. M. van Sark, and M. P. Hekkert, Ren. and Sust. En. Rev. 11, 8 (2007)

21. Y. Charabi and A. Gastli, Renewable Energy 36, 9 (2011)

22. M. Uyan, Ren. and Sust. En. Rev. 28 (2013)

23. J. M. Sánchez-Lozano, J. Teruel-Solano, P. L. SotoElvira, and M. Socorro García-Cascales Ren. and Sust. En. Rev. 24 (2013)

24. N. H. Afgan and M. G. Carvalho, Energy 27, 9 (2002)

25. J.-J. Wang, Y.-Y. Jing, C.-F. Zhang, and J.-H. Zhao, Ren. and Sust. En. Rev. 13, 9 (2009)

26. J. C. Mourmouris and C. Potolias, En. Pol. 52 (2013)

27. J. Szargut, Exergy Method: Technical and Ecological Applications. (WIT Press, 2005)

28. J. Szargut, A. Ziębik, and W. Stanek, Energy Convers Manag, 43 (2002)

29. W. Stanek, Metodyka oceny skutków ekologicznych w procesach cieplnych za pomocą analizy egzergetycznej. (Wydawnictwo Politechniki Śląskiej, 2009)
30. Czamowska, 'Thermoecological cost of products with emphasis on external environmental costs. Doctoral thesis.', Silesian University of Technology, (2014)

31. Szargut and W. Stanek, Energy, 32 (2007)

32. Piekarczyk, L. Czarnowska, K. Ptasiński, and W. Stanek, Energy, 62 (2013)

33. L. Lombardi, E. Carnvale, B. Mendecka, G. Santoni, and W. Stanek, 'Environmental impacts of electricity production of micro wind turbines with vertical axis', in Proceedings of 29th international conference on Efficiency, Cost, Optimisation, Simulation and Environmental Impact of Energy Systems (ECOS) (2016)

34. B. Mendecka and J. Kozioł, Arch. of Thermodyn. 36, 1 (2015)

35. B. Igliński, A. Iglińska, M. Cichosz, W. Kujawski, and R. Buczkowski, Ren. and Sust. En. Rev., 58 (2016)

36. 'SolarGIS (C) 2016 GeoModel Solar, Solar Radiation Map: Global Horizontal Irradiation Map of Poland', 2016. [Online]. Available: http://solargis.info/doc/free-solar-radiation-mapsGHI\#P.

37. 'Order of the Polish Minister of Economy of 13 November 2015 establishing the reference price of electric energy from renewable energy sources in 2016 (in Polish)' Dz. U. z 2015 r. poz. 2063

38. 'Renewable Energy Sources Act (In Polish)' Dz. U. z 2015 r. poz. 478, 2365. 